\title{
High Output Heart Failure Secondary to Aorto- Caval Fistula Treated With an Amplatzer Septal Occluder: Case Report and Review of Literature
}

\author{
Fida Charif ${ }^{1}$, Pierre Nassar ${ }^{2}$, Dani Youssef ${ }^{3}$, Ziad Neghawi ${ }^{4}$, Mohamad Saab $^{5}$ \\ 1. Pulmonary Critical Care Medicine, Beirut Cardiac Institute, Beirut, LBN 2. Adult Cardiology Division, Beirut Cardiac \\ Institute, Beirut, LBN 3. Pediatric Cardiology, Beirut Cardiac Institute, Beirut, LBN 4. Radiology Division, Beirut \\ Cardiac Institute, Beirut, LBN 5. Cardio-vascular Surgery Division, Beirut Cardiac Institute, Beirut, LBN
}

Corresponding author: Fida Charif, mdfcharif@hotmail.com

\begin{abstract}
Aorto-caval fistula (ACF) is a rare cause of high output heart failure (HOHF). $80 \%$ of cases are due to ruptured abdominal aortic aneurysm, while 10 to $20 \%$ are traumatic or congenital. Early diagnosis and treatment are crucial in order to prevent the progression to HOHF. Open surgical repair has been the mainstay therapy of arterio-venous fistulas including aorto-caval fistula; however endovascular approach has become an evolving therapeutic option in the last 20 years. Here, we present a case of high output heart failure secondary to traumatic aorto-caval fistula due to shrapnel injury to the abdomen. Our patient was managed with endovascular approach by the deployment of amplatzer septal occluder that excluded completely the fistula, resulting in the progressive improvement of HOHF. In this manuscript, we review etiologies of high output heart failure and summarize cases of aorto-caval fistula treated with amplatzer septal occluder reported in literature. We also highlight the importance of this endovascular device in the presence of metallic foreign body in the aorta.
\end{abstract}

Review began 03/24/2021 Review ended 04/02/2021 Published 04/12/2021

\section{○ Copyright 2021}

Charif et al. This is an open access article distributed under the terms of the Creative Commons Attribution License CC-BY 4.0., which permits unrestricted use, distribution, and reproduction in any medium, provided the original author and source are credited.
Categories: Cardiac/Thoracic/Vascular Surgery, Cardiology, Radiology

Keywords: aorto-caval fistula, amplatzer septal occluder, high output heart failure

\section{Introduction}

High output heart failure (HOHF), unlike other forms of heart failure (reduced or preserved ejection fraction), is defined as cardiac output (CO) greater than $8 \mathrm{~L} / \mathrm{min}$ or cardiac index (CI) greater than 4.0 $\mathrm{L} / \mathrm{min} / \mathrm{m}^{2}$ along with a low systemic vascular resistance [1]. HOHF is due to increase oxygen demand as a result of hypermetabolic state (e.g exercise, hyperthyroidism, fever, sepsis, pheochromocytoma); or increase cardiac blood flow due to a bypass of arteriolo-capillary bed like arterio-venous fistula (AVF) including aorto-caval fistula (ACF). The ensuing increase in cardiac preload may dramatically increase the cardiac output, mechanical shear stress, remodeling, and cardiac dilatation leading to progressive right and left ventricular failure [2, 3]. Open surgical repair has been the mainstay therapy of AVF, however, the endovascular approach, which was first described in 1999 [4], has become an evolving therapeutic option in the last 20 years with lower mortality and morbidity rate compared to the conventional surgical approach [5]. Amplatzer septal occluder (ASO) is a well-known endovascular treatment approach for intra-cardiac shunt [6], however, its use for the treatment of ACF has been under-reported and was firstly described by Francois Godard et al in 2005 [7]. Here, we report the case of traumatic ACF leading to HOHF and managed successfully by ASO.

\section{Case Presentation}

A 24-year-old man presented to our hospital with four months history of progressively increasing signs and symptoms of right-side heart failure. He had an abdominal shrapnel injury to the abdomen for which he underwent a partial colectomy via a laparotomy five months prior to the beginning of the first symptoms of shortness of breath. On admission his physical examination was remarkable for tachypnea (24/min), pulse oxygen saturation $92 \%$ on room air, neck vein distension, markedly decreased breath sounds over the right lung field. The abdominal examination showed a periumbilical palpable thrill with a systolo-diastolic murmur. We also noted bilateral lower limb pitting edema. His chest $\mathrm{x}$-ray showed enlarged right heart cavities and right pleural effusion [Figure 1]. 


\section{Cureus}

\section{RT /M.S}

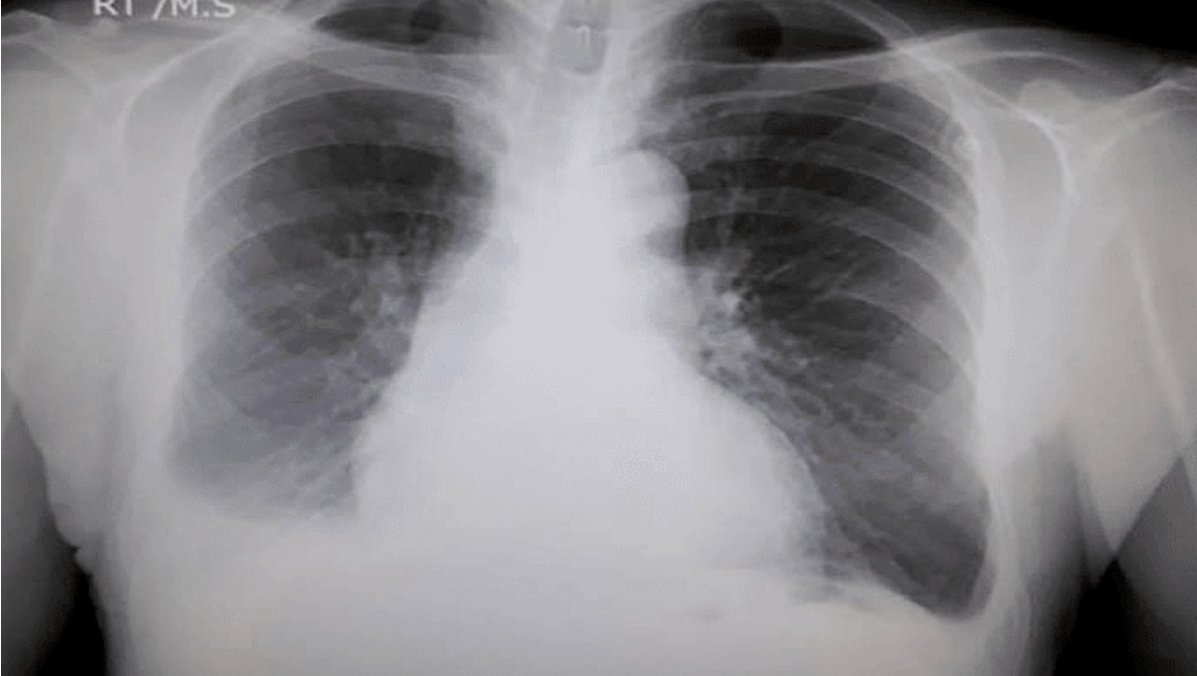

\section{FIGURE 1: Chest radiograph PA view}

Shows mild right pleural effusion, mild cardiomegaly and dilated right heart cavities

The echocardiography showed severely dilated right heart cavities with mildly impaired systolic function (TAPSE $14 \mathrm{~mm}$ ) [Figure 2].

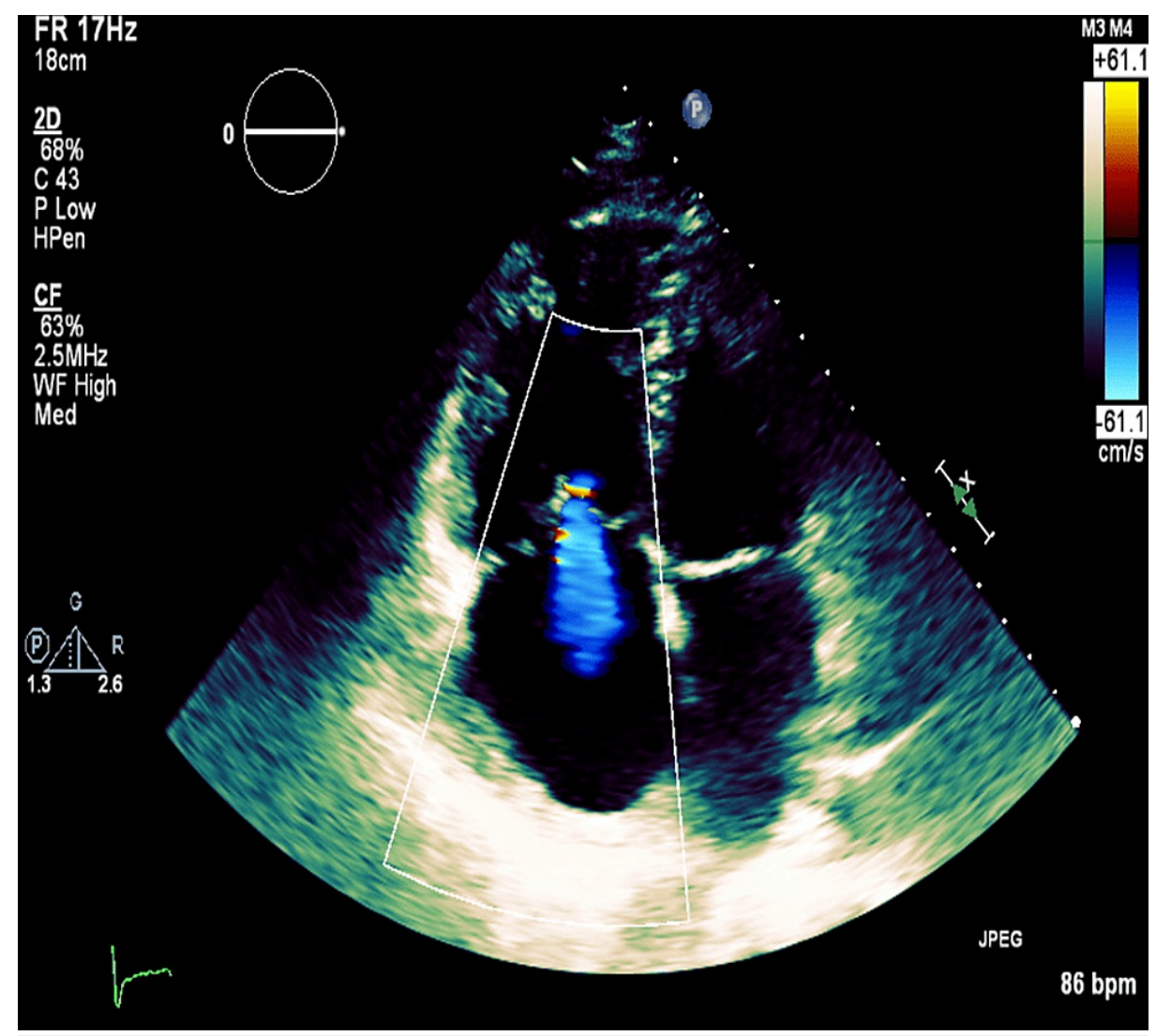

FIGURE 2: Transthoracic echocardiogram

Transthoracic echocardiogram Four chamber view shows severe dilatation of right heart cavities.

We also noted mild tricuspid valve regurgitation. Left side chambers and valves were normal. A right heart 


\section{Cureus}

catheterization (RHC) showed a high cardiac output, cardiac index and markedly decreased systemic vascular resistance and severe pulmonary hypertension [central venous pressure (CVP) $18 \mathrm{mmHg}, \mathrm{CO} 10.8 \mathrm{~L} / \mathrm{min}$, CI $6.07 \mathrm{~L} / \mathrm{min} / \mathrm{m}^{2}$, systemic vascular resistance (SVR) 348 Dynes $/ \mathrm{sec} / \mathrm{cm}^{-5}$, mean pulmonary artery pressure (mPAP) $45 \mathrm{mmhg}$, pulmonary vascular resistance (PVR) 460 Dynes $/ \mathrm{sec}^{-\mathrm{cm}^{-5}}$. A computed tomography angiography of the abdomen (CTA) showed an ACF of $(1.2 \mathrm{~cm})$ of a diameter just above the aortic bifurcation with severe dilatation of the inferior vena cava $(46 \mathrm{~mm})$ and the right iliac vein, we also noted the presence of remaining shrapnel in the aorta [Figure 3,4].

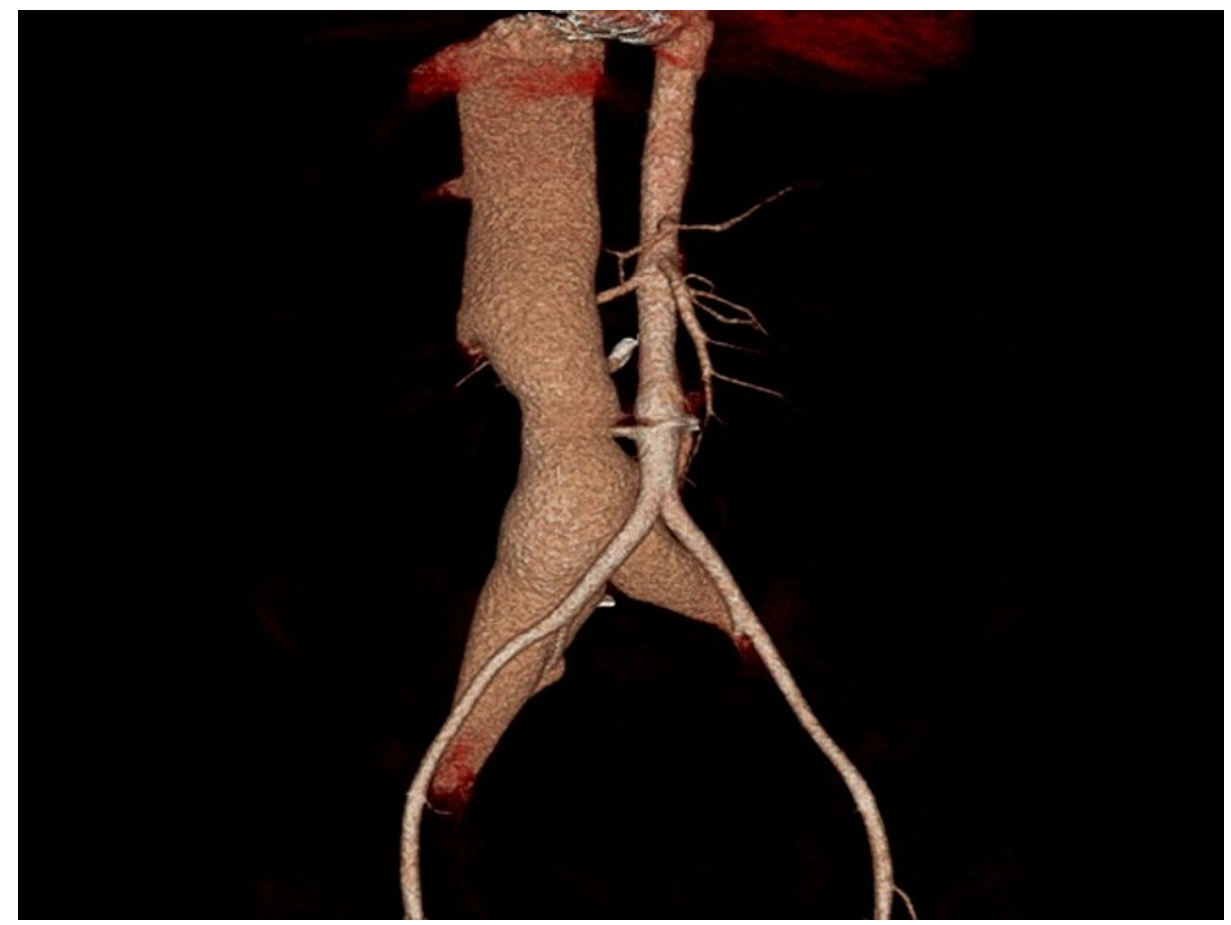

\section{FIGURE 3: Computed tomography angiography (volume rendering)}

A communication between the aorta ( just above the aortic bifurcation) and the inferior vena cava. It shows the severely dilated inferior vena cava. 


\section{Cureus}

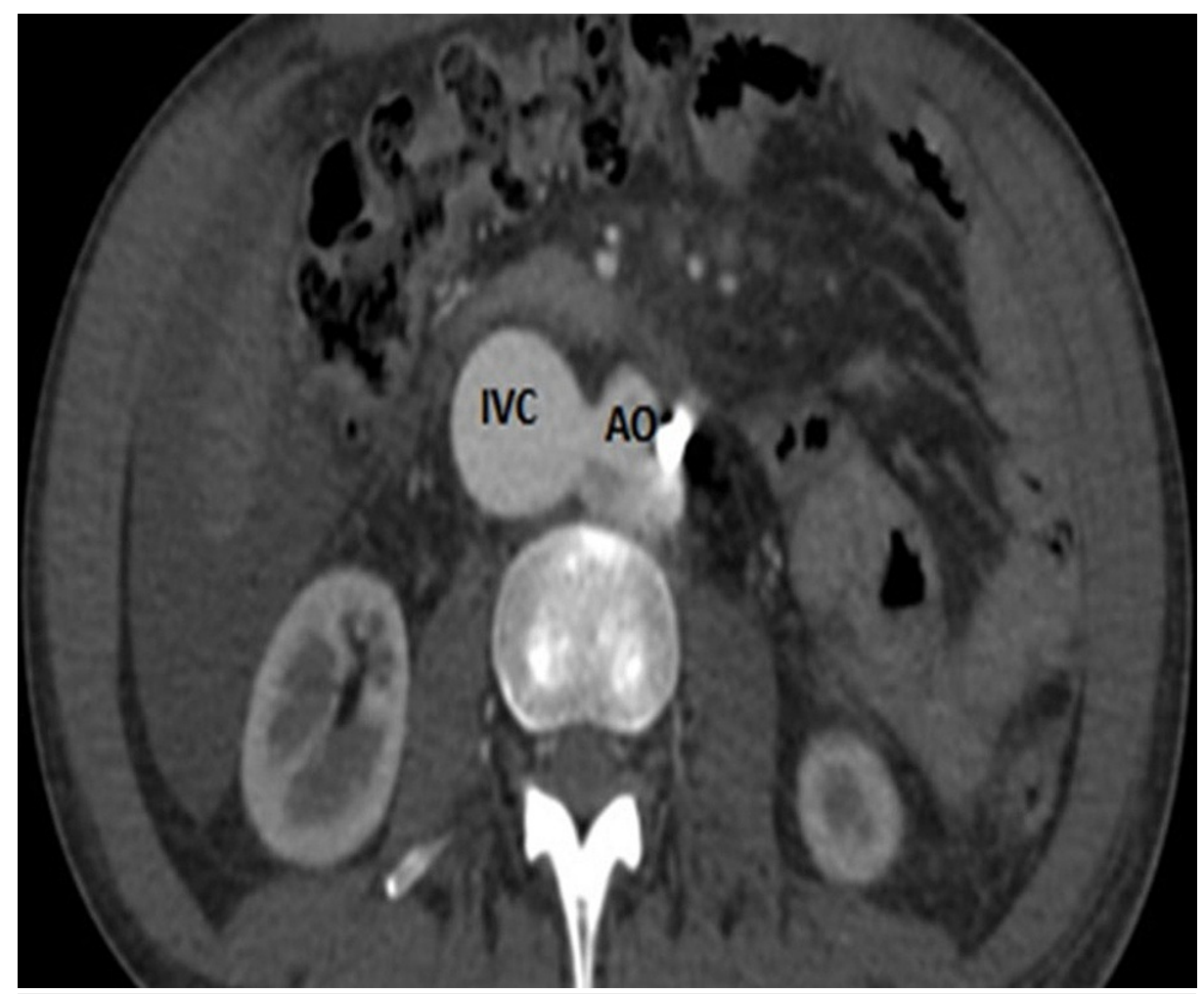

\section{FIGURE 4: Computed tomography angiography (Axial view)}

Shows the communication between the aorta (AO) and the inferior vena cava (IVC) during the arterial phase. we also note the presence of the foreign material in the AO.

All these findings were consistent with the diagnosis of HOHF secondary to ACF due to a remote abdominal shrapnel injury. After a multidisciplinary discussion of our cardiovascular team, we decided to close the ACF with an ASO device. After a double puncture of the left femoral artery and the right femoral vein, a pigtail catheter was introduced through the left femoral artery and positioned in the aorta just above the ACF. While the angiography visualized the large ACF, the delivery system was introduced through the left femoral vein reaching the aorta via the ACF, and then the ASO device (occlutech $10.5 \mathrm{~mm}$ ) was deployed, releasing the left disc in the aorta and the right disc in the inferior vena cava [Video 1].

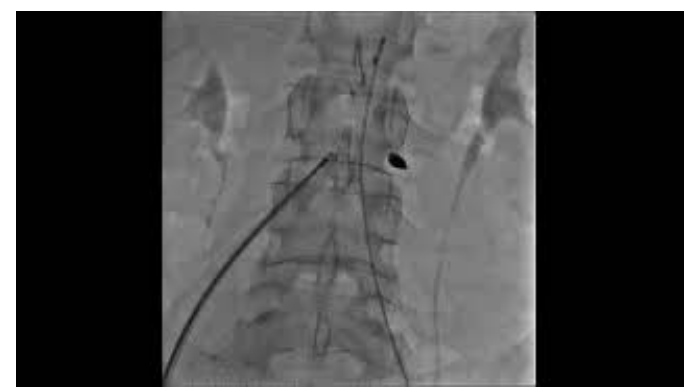

\section{VIDEO 1: Deployment of the Amplatzer Septal Occluder}

Angiography shows the deployment of the amplatzer septal occluder

View video here: https://www.youtube.com/watch?v=v5hLJRXj1Sw\&t=4s

An angiography showed the well-positioned ASO device and a mild persistent endoleak. A few days later, our patient's symptoms markedly improved, and a normal abdominal examination with complete disappearance of the thrill and the systole-diastolic murmur. Repeat echocardiogram showed markedly decreased diameter of right heart cavities, inferior vena cava $(26 \mathrm{~mm})$, improvement of right ventricular systolic function (TAPSE $18 \mathrm{mmHg}$ ), and disappearance of tricuspid regurgitation. CTA at three months and angiography at six months follow-up showed complete exclusion of the ACF [Figure 5] and well-positioned [Figure 6]. Repeat RHC at six months confirmed the resolution of HOHF (CVP 4mmhg, CO $4.2 \mathrm{~L} / \mathrm{min}, \mathrm{CI} 3 \mathrm{~L} / \mathrm{min} / \mathrm{m}^{2}$, 


\section{Cureus}

SVR 1200 Dynes/sec/ $\mathrm{cm}^{-5}$, mPAP $18 \mathrm{mmHg}$, PVR 150 Dynes $/ \mathrm{sec} / \mathrm{cm}^{-5}$ )

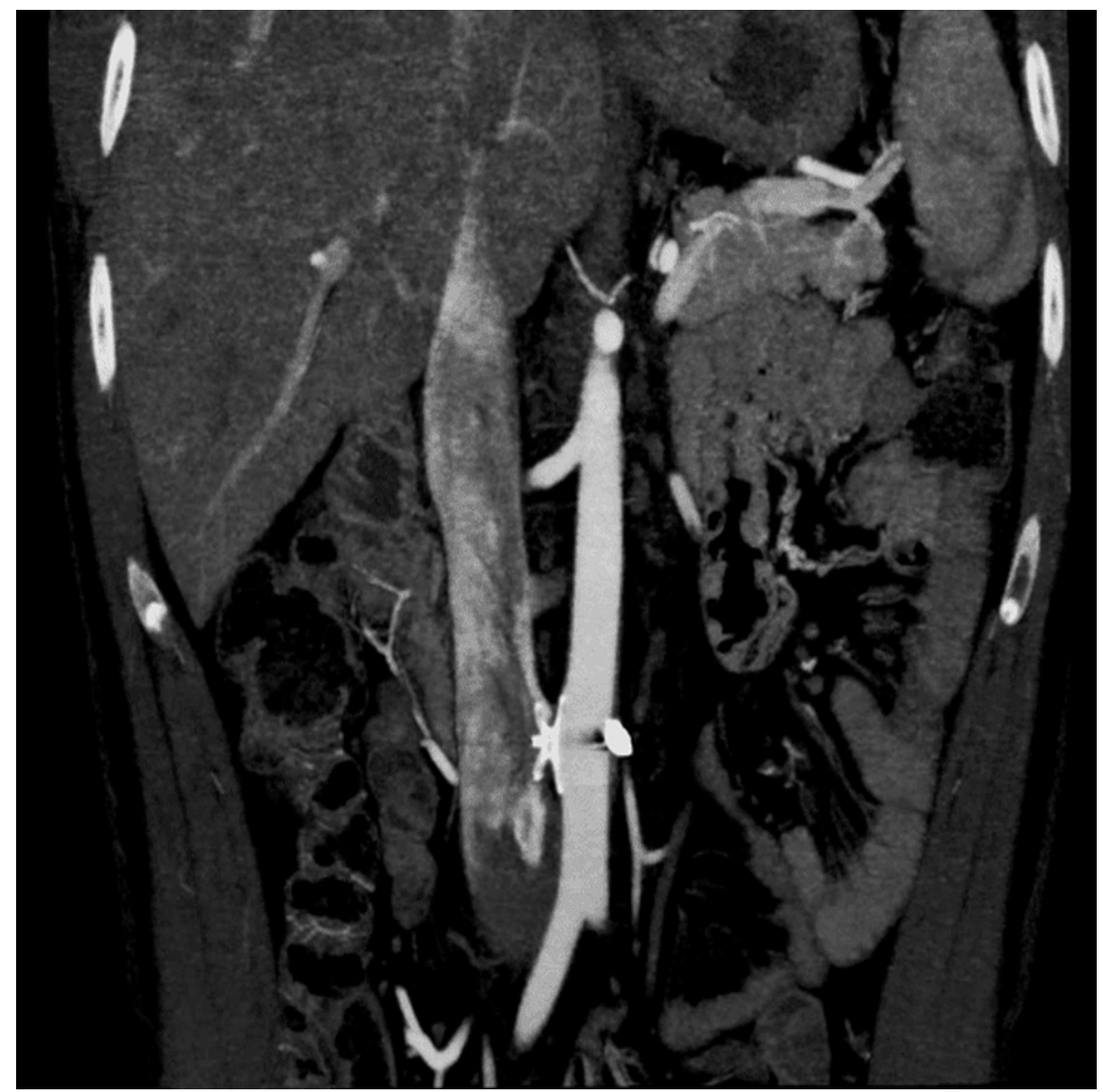

FIGURE 5: Computed tomography angiography of the abdomen (coronal view)

Exclusion of the fistula with mild endoleak and well positioned ASO. 


\section{Cureus}

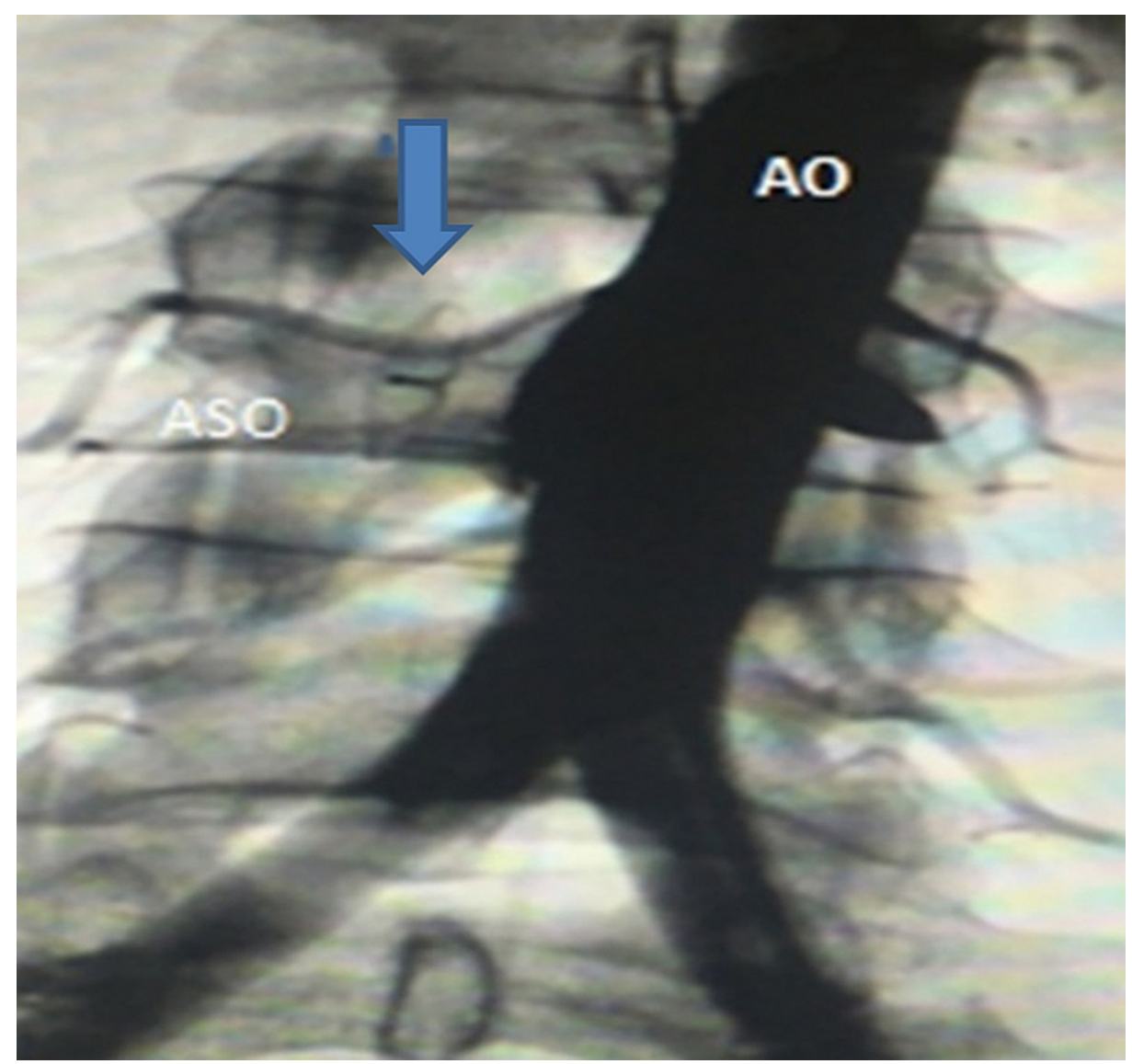

\section{FIGURE 6: Angiography of the aorta}

Complete exclusion of the Aorto-caval fistula with stable position of the amplatzer septal occluder at 6 months follow up

\section{Discussion}

ACF is one of the very rare causes of HOHF. 80-90\% of ACF are due to ruptured abdominal aortic aneurysm (AAA) into the inferior vena cava, although the incidence is only $2-7 \%$ of all cases of AAA; while traumatic and iatrogenic causes represent 10-20\% [8]. Clinical manifestations include back pain, symptoms, and signs of HOHF, abdominal bruit, palpable abdominal mass, peripheral edema, liver, and renal failure. Traumatic ACF was first described in 1831, while Cooley et al [9] reported the first successful surgical repair in 1954. Careful history and physical examinations raise the suspicion of ACF. Diagnosis is usually confirmed by duplex ultrasound and or computed tomographic angiography (CTA). Dabbouseh NM et al [10], Srisuwan T et al [11], Waldrop JL et al [12], reported three cases of ACF secondary to penetrating trauma. The authors described a delayed diagnosis and successful endovascular repair of ACF. Recent reports showed lower mortality and morbidity rate compared to the conventional surgical approach [5]. However, a contemporary review of both endovascular and open ACF repair showed that the endovascular approach was not associated with lower complications or mortality rate [13]. These results were attributed to the higher rate of endoleak (50\%) and delayed ACF diagnosis reported by the cases included in this review. The use of ASO to treat a residual ACF following stent deployment in patients with ruptured AAA has also been reported [14]. Our patient was treated by the deployment of ASO; we estimated that the deployment of a stent-graft would be at risk of rupture by the remained shrapnel in the aorta post abdominal injury. The other option was the vascular plug which was excluded due to its small size, the disadvantage of being compressed and protruding into the aorta or IVC. The use of ASO to treat ACF was first reported by Francois Godard et al [7] who described the first two cases of ACF that were treated successfully with ASO. Furthermore, ACF complicating a stent-graft deployment during an AAA repair has been also described and was therefore successfully treated with ASO $[15,16]$. ASO is an effective therapeutic option of ACF, especially in patients post-traumatic abdominal injury with remaining shrapnel material.

\section{Conclusions}

HOHF and ACF are both rare and reversible conditions. ASO seems to be a promising endovascular technique for the treatment of ACF and/or exclusion of a residual endoleak following a stent-graft deployment. Our case highlights the importance of this endovascular device in the treatment of ACF especially In the presence 
of metallic foreign body (shrapnel) in the aorta, since the use of a stent-graft may lead to its fracture during deployment. Further studies using the ASO for treatment of ACF are needed.

\section{Additional Information \\ Disclosures}

Human subjects: Consent was obtained or waived by all participants in this study. Conflicts of interest: In compliance with the ICMJE uniform disclosure form, all authors declare the following: Payment/services info: All authors have declared that no financial support was received from any organization for the submitted work. Financial relationships: All authors have declared that they have no financial relationships at present or within the previous three years with any organizations that might have an interest in the submitted work. Other relationships: All authors have declared that there are no other relationships or activities that could appear to have influenced the submitted work.

\section{Acknowledgements}

We acknowledge our radiology technician Mr Yaakoub Salman for his help.

\section{References}

1. Reddy YNV, Melenovsky V, Redfield MM, Nishimura RA, Borlaug BA: High-output heart failure: a 15-year experience. J Am Coll Cardiol. 2016, 68:473-482. 10.1016/j.jacc.2016.05.043

2. Mehta PA, Dubrey SW: High output heart failure. QJM. 2009, 102:235-41. 10.1093/qjmed/hcn147

3. Sunagawa K, Sugimachi M, Todaka K, et al.: Optimal coupling of the left ventricle with the arterial system . Basic Res Cardiol. 1993, 88:75-90.

4. Parodi JC, Schönholz C, Ferreira LM, Bergan J: Endovascular stent-graft treatment of traumatic arterial lesions. Ann Vasc Surg. 1999, 13:121-9. 10.1007/s100169900230

5. Brightwell RE, Pegna V, Boyne N: Aortocaval fistula: current management strategies . ANZ J Surg. 2013, 83:31-35. 10.1111/j.1445-2197.2012.06294.x

6. Rao SS, Scaff TL, Gurley J, Saha S: Clinical use of the amplatzer device in the management of intracardiac defects: a single-center experience. Int J Angiol. 2018, 27:39-42. 10.1055/s-0038-1626718

7. Godart F, Haulon S, Houmany M, Francart C, Brevière GM, Rey C, Koussa M: Transcatheter closure of aortocaval fistula with the amplatzer duct occluder. J Endovasc Ther. 2005, 12:134-7. 10.1583/04-1332.1

8. Akwei S, Altaf N, Tennant W, MacSweeney S, Braithwaite B: Emergency endovascular repair of aortocaval fistula--a single center experience. Vasc Endovascular Surg. 2011, 45:442-6. 10.1177/1538574411407087

9. Takkar C, Choi L, Mastouri N, Kadambi PV: Aortocaval fistula: a rare cause of venous hypertension and acute renal failure. Case Rep Surg. 2012, 2012:487079. 10.1155/2012/487079

10. Dabbouseh NM, Mason PJ, Patel PJ, Rossi PJ: Endovascular repair of delayed traumatic aortocaval fistula . J Vasc Surg Cases Innov Tech. 2019, 5:467-71. 10.1016/j.jvscit.2019.06.012

11. Srisuwan T, Kanjanavanit R, Rerkasem K: Endovascular aortic stenting in patients with chronic traumatic aortocaval fistula. Ann Vasc Dis. 2013, 6:741-4. 10.3400/avd.cr.13-00078

12. Waldrop JL Jr, Dart BW 4th, Barker DE: Endovascular stent graft treatment of a traumatic aortocaval fistula . Ann Vasc Surg. 2005, 19:562-5. 10.1007/s10016-005-5025-7

13. Orion KC, Beaulieu RJ, Black JH 3rd: Aortocaval fistula: is endovascular repair the preferred solution? . Ann Vasc Surg. 2016, 31:221-8. 10.1016/j.avsg.2015.09.006

14. von Heesen M, Sperling J, Plusczyk T, Bücker A, Katoh M, Schilling MK, Moussavian MR: Multimodal approach in coincidence of covered ruptured abdominal aortic aneurysm and aortocaval fistula (Article in German). Dtsch Med Wochenschr. 2010, 135:2296-9. 10.1055/s-0030-1267513

15. Lee P, Sheehan BM, Gordon I, et al.: Novel utility of amplatzer septal occlusion device to treat persistent aortocaval fistula following ruptured endovascular aortic aneurysm repair (revar). Ann Vasc Surg. 2020, 65:283.e7-283.e11. 10.1016/j.avsg.2019.10.079

16. LaBarbera M, Nathanson D, Hui P: Percutaneous closure of aortocaval fistula using the amplatzer muscular vsd occluder. J Invasive Cardiol. 2011, 23:343-344. 